\title{
Mary Seacole e Maria Soldado: enfermeiras negras que fizeram história
}

\author{
Maria Seacole y María Soldado: enfermeras negras \\ que hicieron historia
}

\section{Mary Seacole and Mary Soldier: black nurses who made history}

\author{
Lily Löw ${ }^{1}$, Taka Oguisso ${ }^{2}$
}

${ }^{1}$ Enfermeira. Mestranda do Programa de Pós-Graduação em Enfermagem/EEUSP. Pesquisadora do Grupo de Pesquisa História e Legislação da Enfermagem - ENO/EEUSP/CNPq. E-mail: lilylow@usp.com.br. (11) 962942356

${ }^{2}$ Professora Titular da Escola de Enfermagem da Universidade de São Paulo. Líder do Grupo de Pesquisa História e Legislação da Enfermagem - ENO/EEUSP/CNPq. Av. Dr. Enéas de Carvalho Aguiar, 419. (11)30617552 E-mail: takaoguisso@usp.com.br Cómo citar este artículo en edición digital: Löw, L. y Oguisso, T. (2014) Mary Seacole e Maria Soldado: enfermeiras negras que fizeram história. Cultura de los Cuidados (Edición digital) 18, 38. Disponible en: http://dx.doi.org/10.7184/cuid.2014.38.9>

\section{Correspondencia: ENO/EEUSP/CNPq. Av. Dr. Enéas de Carvalho Aguiar, 419. (11) 30617552 \\ Correo electrónico:: lilylow@usp.com.br. \\ Recibido: 10/10/2013; Aceptado: 11/12/2013}

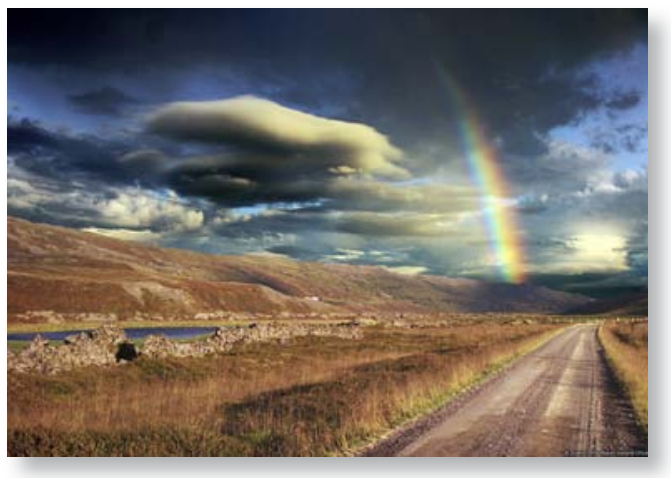

\section{ABSTRACT}

This study aims at giving visibility to two women; Mary Jane Seacole and Mary Soldier, who have experienced racism in their actions, but they knew how to face the unknown boundaries, overcoming them in search of their lives ideals. Through the documental research method, it is intended to rescue the history of these black women, placing them as models for the nursing professional history and also among the forerunners of the modern nursing.

Keywords: Nursing History, Racism, Caregivers

\section{RESUMEN}

Este estudio tiene por objetivos dar visibilidad a dos mujeres: Mary Jane Seacole y Maria Soldado, quienes han sufrido racismo en sus acciones, pero supieron desbravar las fronteras del desconocido, superarlas em la búsqueda de los ideales de sus vidas. A través del método de investigación documental, pretendese rescatar la historia de estas mujeres negras, posicionandolas como modelos de la historia profesional de enfermería y colocarlas entre las precursoras de la enfermería moderna.

Palabras clave: Historia de la Enfermería, el racismo, los cuidadores

\section{RESUMO}

Este estudo tem por objetivos dar visibilidade a duas mulheres - Mary Jane Seacole e Maria Soldado - que sofreram racismo em suas ações, mas souberam desbravar as fronteiras do desconhecido, superá-las em busca dos ideais de suas vidas. Pretende-se através do método de pesquisa documental, resgatar a história dessas mulheres negras, posicionan- 
do-as como modelos da história profissional da enfermagem, colocando-as entre as precursoras da enfermagem moderna.

Palavras-chave: História da Enfermagem, Racismo, Cuidadores.

\section{INTRODUÇÃO}

O estudo pretende dar visibilidade a duas mulheres negras que em épocas diferentes foram consideradas enfermeiras pela imprensa. A proposta é divulgar a ação dessas mulheres que, em seu tempo e nas circunstâncias e condições existentes, procuraram atender às necessidades humanas, consubstanciando o que se convencionou chamar de enfermagem pré-profissional, vale dizer, um tipo de cuidado baseado mais na intuição e no espírito de servir do que em ganhos materiais ou até sociais, mesmo porque não havia ainda qualquer tipo de instrução formal capaz de qualificar o trabalho do cuidador, na época de Mary Seacole. Já na época de Maria Soldado, existiam algumas poucas escolas de enfermagem no Brasil, mas havia ainda restrição à admissão de negros. Este estudo focaliza personagens que prestaram cuidados baseando-se em um saber intuitivo, constituído pela prática, e não pela formação profissional (Oguisso, 2011).

Essas duas mulheres conhecidas como Mary Jane Seacole e Maria Soldado viveram em épocas e países distintos, porém existia algo em comum entre elas: eram negras e participaram ativamente, atuando como cuidadoras e enfermeiras na guerra e sofreram discriminação racial.

Descrever o trabalho dessas duas mulheres é uma forma de resguardar no presente essa história para que não se torne um passado a ser esquecido, escondido ou ignorado pelas gerações de hoje e do futuro, visto que dificil- mente as publicações conseguem sobreviver ao massacre cultural imposto pela classe dominante, constituída majoritariamente de indivíduos brancos (Jezuino, 1997).

Há que se considerar também a quase inexistência de publicações sobre a importância do trabalho de enfermeiras negras para o desenvolvimento da enfermagem mundial e brasileira.

Igualmente não pode ser esquecido que, tanto no mundo como no Brasil, o cuidado foi exercido por homens e mulheres comuns, escravizados ou não, como o caso das amas de leite, babás e mães pretas, que se dedicavam ao cuidado de crianças, idosos, gestantes e parturientes.

Por muito tempo essa história foi negligenciada e pouco analisada, constituindo-se, pois, em amplo campo para estudos em história da enfermagem. Personagens de uma história em construção, esses cuidadores/ enfermeiros, homens e mulheres, merecem respeito e reverência por terem se dedicado, de alguma forma, a feridos e doentes, crianças e idosos (Oguisso, 2011).

Entre os muitos enfermeiros afro-americanos que contribuíram para a profissão, poucos são tão destacados como Mary Elizabeth Carnegie - uma enfermeira inovadora que defendeu a causa de enfermeiros afro-americanos. Nascida em 19 de abril de 1916, em Baltimore (Maryland), foi exemplo do poder negro, pois conseguiu quebrar barreiras raciais e abriu caminho para o avanço de enfermeiras afro-americanas. Dra. Carnegie foi a primeira enfermeira negra nomeada para o Conselho de Administração da Associação de Enfermeiras da Flórida, entre outros inúmeros reconhecimentos. Escreveu vários livros e artigos entre os quais "O Caminho que trilhamos: negros na enfermagem" que recebeu várias premiações. Dra. Carnegie morreu em 20 de fevereiro de 2008 em Chevy Chase, Maryland Buried ( Tompkins- 
-McCaw, 2013). Nos Estados Unidos, vários outros negros se notabilizaram, tanto na área civil como militar, como Gloria Smith - coordenadora dos Programas de Saúde da Fundação Kellogg, em 1991; Barbara Nichols foi primeira negra a ser eleita presidente da Associação Americana de Enfermeiras, em 1978 e re-eleita em 1980, Coronel Mary Rozina Boyd, Coronel Clara B. Wallace, além de muitas outras.

Justifica-se tal investigação pela essência do trabalho do enfermeiro que é o cuidar/cuidado que não deve sofrer nenhum tipo de alteração em seu procedimento, na conduta, no trabalho em equipe, nas tomadas de decisões independentemente da cor da pele de quem cuida ou de quem é cuidado (Santiago, 2010).

No ambiente de trabalho, o racismo, na maioria das vezes está embutido no assédio moral, em piadas racistas e em outras formas de discriminação. Por tais razões é preciso refletir e ampliar ações em defesa da igualdade racial (Sandra,2013).

"A atribuição de significado social às propriedades físicas, desde a infância, resulta da compreensão que, paulatinamente, vai se adquirindo em face dos sinais de aceitação ou de rejeição, implícitos nas atitudes e nas condutas dos adultos" (Silva, 2002).

Compreender o racismo pela internalização de imagem desfavorável de si mesmo, a inferiorização e a diferenciação presentes no fenômeno do racismo, relaciona a identidade pessoal com a identidade social, concebendo-a como produto social resultante de situação de conflito "envolvendo discriminação, exclusão social, exploração e opressão individual ou coletiva” (Silva, 2002).

Para Munanga, "o racismo nunca foi um fenômeno estático e no, seu dinamismo atual, recorre com frequência à hipervalorização das diferenças ou das identidades culturais para re- estruturar-se e reformular-se" (Munanga, 1990).

Sentimentos racistas e preconceituosos são geradores de práticas excludentes e discriminatórias, cujo efeito social interfere na assistência de enfermagem, pois favorece a imposição de juízos de valor em detrimento de juízos de fato, ferindo princípios de equidade e direitos humanos, desfavoráveis para o desenvolvimento de modelos assistenciais existentes, preconizados por políticas públicas de saúde como o Sistema Único de Saúde - SUS e o Programa Nacional de Humanização - PNH (Santiago, 2010).

O presente estudo tem por objetivo dar visibilidade a essas duas mulheres - Mary Jane Seacole e Maria Soldado - que sofreram racismo em suas ações, mas souberam desbravar as fronteiras do desconhecido, driblá-lo e ir em busca do ideal de suas vidas. Pretende-se, pois, resgatar a história dessas mulheres negras, posicionando-as como figuras de proa na história profissional da enfermagem, colocando-as entre as precursoras da enfermagem moderna.

No contexto da pré-profissionalização da enfermagem, existia certo olhar de indiferença ou desconfiança para com pessoas leigas que se dedicavam ao cuidado de doentes ou feridos, crianças ou idosos, mesmo em relação àquelas pessoas que deixaram seus nomes na história do Brasil. Porém, quando esse cuidado era prestado como parte de vocação religiosa, a pessoa era admirada por realizar um ato de caridade cristã. É certo, porém, que reais ou ficcionais, autoridades e mesmo a literatura lhes atribuíram o título de enfermeiro ou enfermeira (Oguisso, 2011).

A enfermagem é tão antiga quanto à existência do ser humano, pois a arte de curar nasceu do desejo de proteção e ajuda ao débil, ao doente e ao desamparado. 13 refere que qualquer expressão de tal natureza estará 
sempre vinculada à profissão de enfermeira. A mãe que assiste ao filho enfermo dando-lhe cuidados necessários constitui sempre a visão que surge ao pensar na primeira enfermeira da humanidade. O homem primitivo acreditava que as doenças provinham de causas sobrenaturais, daí o forte vínculo que existia entre doença e divindades e a crença entre os gregos de que, indo ao templo do deus Esculápio (ou Asclépio) no século XIII (AC), poderiam recobrar a saúde. Assim, na Grécia antiga somente aos homens cabia discutir temas filosóficos e as mulheres dedicavam-se apenas aos cuidados dos filhos e dos doentes, tornando-se assim as primeiras "médicas", "anatomistas" e enfermeiras da história ocidental. Essas mulheres realizavam partos, cuidavam de abortos e tratavam doentes com plantas e ervas medicinais (Borenstein, 1998).

Historicamente, portanto, pode-se dizer que os cuidados dispensados a pessoas na própria habitação foi uma das mais antigas ainda que rudimentares - formas de atenção ao ser humano. E os cuidados existiram desde que surgiu a vida, uma vez que seres humanos - como todos os seres vivos - sempre precisaram de cuidados, vale dizer, "cuidar é o ato de vida que tem como fim, primeiro e antes de tudo, permitir que a vida continue a desenvolver-se e, assim, lutar contra a morte: morte do individuo, morte do grupo, morte da espécie" (Collière, 1989).

Na trajetória evolutiva da sociedade, a ação de cuidar ou "tomar conta" de pessoas, no sentido de ajudá-las a cuidar de si e de atender às suas necessidades vitais, confunde-se no tempo com o trabalho da mãe que nutre os seus filhos e deles cuida. Da mesma forma, como mulher deveria cuidar de outras pessoas dependentes, como idosos, feridos e doentes. A proteção materna instintiva, nestes termos, pode ser considerada como a primeira forma de manifestação de cuidados do ser humano com seus semelhantes (Oguisso, 2011).

$\mathrm{Na}$ medida em que grupos humanos abandonavam o nomadismo e se fixavam em determinado território, formando os primeiros assentamentos humanos, surgiam primitivas organizações sociais, nas quais homens e mulheres assumiam funções distintas nesse embrião de sociedade. Homens dedicavam-se à caça e pesca com todos os riscos inerentes a essas tarefas, e mulheres voltavam suas ações para as lides domésticas. "Ambos, porém, dedicados a cuidar, isto é, "manter a vida dos seres humanos como objetivo de permitir a reprodução e a perpetuidade da vida do grupo" (Collière, 1989).

O reconhecimento legal, social e intelectual da profissão, como permite observar José Siles Gonzáles (1999), exige um olhar que apreenda não apenas o saber-fazer. Os conteúdos da história da enfermagem, ao permitir o reconhecimento do passado, dos percursos que levavam homens e mulheres a projetar a arte de ciência do cuidado como algo imprescindível à vida moderna, sempre orientou o profissional (Siles, 1999).

Assim, devemos projetar luzes sobre essas mulheres: Mary Jane Seacole e Maria Soldado que fizeram parte dessa história.

\section{MARY JANE SEACOLE}

Nasceu em 1805, em Kingston, atual capital da Jamaica, uma ilha situada no Caribe, na época em que ela era ainda uma colônia inglesa. Seacole era filha de mãe negra jamaicana e pai branco, escocês, oficial do exercito britânico. Mary Seacole era considerada crioula e possuía direitos políticos limitados, mas recebeu uma boa educação e fazia parte da alta sociedade jamaicana, porém isto não impediu 
que ela sofresse racismo no decorrer de sua trajetória na enfermagem.

Mary Seacole era uma pessoa tímida e dócil, carismática, determinada, perseverante e lutadora. Herdou da mãe conhecimentos sobre ervas medicinais e tinha adquirido suas habilidades de enfermagem nas epidemias de febre amarela e cólera que ela havia ajudado a combater em seu país e em países vizinhos, como Bahamas, Haiti, Cuba e Panamá. Nesses países ela aprimorou seus conhecimentos e aprendeu a usar plantas e ervas locais para tratar os doentes.

Ao tomar conhecimento de que Florence Nightingale estava selecionando pessoas para ir cuidar de soldados feridos da Guerra da Crimeia (1853-56), Mary Seacole se inscreveu, porém seu pedido foi negado por Florence.

Inconformada com a negativa de Florence Nightingale, mas determinada a ir cuidar dos feridos na Guerra da Crimeia, Seacole resolveu arrecadar fundos para sua própria viagem para Scutari, onde ficariam sediadas as voluntárias da Guerra de Crimeia.

Seacole com os recursos arrecadados montou um hotel chamado British Hotel que ficava a poucos quilômetros da frente de batalha, onde vendia bebida e comida para os soldados britânicos e com o dinheiro arrecadado ajudava nos cuidados médicos que os feridos de guerra precisavam.

Seacole atendia os soldados em campo de batalha e, diversas vezes foi encontrada cuidando de soldados, de ambos os lados, enquanto a batalha acontecia. Ficou conhecida como a Mãe Seacole entre os soldados e feridos de guerra.

Com o fim da guerra em 1856, Mary Seacole retornou à Inglaterra. Porém, logo quis partir para a Índia para trabalhar como enfermeira, porém desta vez, não conseguiu angariar os fundos necessários e morreu em 1881. O Museu Florence Nightingale, em Londres, reconheceu seu importante papel na enfermagem e em homenagem permanente a ela exibe um busto de bronze na entrada, para que seus feitos não sejam esquecidos. Morreu em 14 de maio de 1881, em Londres.

De fato, suas iniciativas e habilidades no cuidado aos soldados feridos fizeram-na merecedora de várias homenagens conforme relatou em sua autobiografia, "Aventuras maravilhosas da Sra. Seacole em muitas terras" (1857). É um vívido relato de suas experiências, e é uma das primeiras autobiografias de uma mulher de raça mista.

Porém, no Brasil pouco se sabe ou se estuda sobre Mary Seacole cujos seus feitos continuam no anonimato.

\section{MARIA SOLDADO}

Noventa anos depois do nascimento de Mary Seacole, nasceria em Limeira, no dia $1^{\circ}$ de dezembro de 1895, Maria Jose Barroso, depois conhecida como "Maria Soldado".

Maria Soldado viveu num contexto histórico onde os cientistas propagavam a ideia da eugenia, um movimento de caráter intelectual e racista que, desde a campanha abolicionista, defendia o ideal do embranquecimento do povo brasileiro (Garcia, 1993).

Um dos maiores propagandista da eugenia foi o médico Renato Kehl onde uma das principais marcas de seu discurso era o seu pessimismo quanto ao futuro da nação brasileira, para ele, a miscigenação racial conduzia o Brasil para uma catástrofe. Para Renato Kehl os cruzamentos "promíscuos" eram produtos de indivíduos incapazes para o progresso da nação. O pessimismo em relação ao perfil racial brasileiro poderia ser superado se as ideias e práticas do eugenismo nacional fossem adotadas. Recebida como uma arma capaz de promover uma "nova ordem social” pela melhoria da raça, a eugenia 
encontrou em Renato Kehl, um de seus mais importantes divulgadores ( Santos, 2005).

Independentemente aos conflitos e crises que o país estava vivendo, Maria Jose Barroso, cognominada depois como Maria Soldado, não hesitou em defender a causa paulista, pois quando eclodiu a Revolução Constitucionalista de 1932, em São Paulo, ela trabalhava como cozinheira da família Penteado Mendonça e abandonou seu serviço para ir à guerra. Maria Jose Barroso, ou "Maria Soldado", nasceu em Limeira, em $1^{\circ}$ de dezembro de 1895. Ingressou na guerra civil, inicialmente, acompanhando os combatentes como "enfermeira" da Legião Negra. Foi reconhecida pelos seus feitos e muitos jornais da época noticiaram sua bravura. Em 5 de setembro de 1932, o jornal A Gazeta referiu-se a "uma mulher de cor, alistada na Legião Negra, vencendo toda sorte de obstáculos e as durezas de uma viagem acidentada, uniu-se aos seus irmãos negros em pleno entrincheiramento na frente do sul, descrevendo a página mais profundamente comovedora, mais profundamente brasileira, da campanha constitucionalista, ao desafiar a morte nos combates encarniçados e mortíferos para o inimigo, MARIA DA LEGIÃO NEGRA! Mulher abnegada e nobre da sua raça”.

Todos os que participaram, direta ou indiretamente, da Revolução Constitucionalista de 1932 lembram-se dos feitos heroicos de "Maria Soldado" nas frentes de batalha, como integrante da Legião Negra, onde também empunhou o fuzil e lutou contra as forças federais que defendiam a ditadura de Getulio Vargas.

Em 1957, por ocasião do jubileu de prata do movimento constitucionalista, ela foi escolhida como mulher "símbolo de 32".

Maria Jose Barroso ou Maria Soldado faleceu em São Paulo, no dia 11 de fevereiro de 1958. Seus restos mortais repousam no panteão dos heróis da Revolução, simbolizado pelo grande obelisco no Parque do Ibirapuera, na cidade de São Paulo.

Porém, como Mary Seacole, pouco se sabe ou se estuda sobre esta mulher que se tornou uma figura relevante da enfermagem pré- profissional no Brasil. Daí a importância de resgatar essas personagens que na humildade de seu trabalho souberam engrandecer o núcleo da ação profissional de enfermagem, qual seja a ação de cuidar de pessoas. Trazê-las à luz e dar-lhes visibilidade pelo que desempenharam na história, seria a homenagem mínima que pode ser prestada a duas figuras que souberam honrar a ação de cuidar, fazendo desta a motivação de suas vidas em prol do ser humano em sofrimento acarretado pela guerra.

\section{CONSIDERAÇÕES FINAIS}

Na verdade, a invisibilidade da mulher negra na sociedade constitui uma consequência da precária literatura, reflexo também do pouco interesse sobre essa temática por parte de pesquisadores. Pode-se observar que mesmo havendo um espaçamento de noventa anos entre o nascimento de Mary Seacole (1805) para Maria Soldado (1895), pouco foi feito em relação ao racismo no Brasil e no mundo.

Felizmente, porém começam a surgir enfermeiros, historiadores e sociólogos interessados em aprofundar análises e estudos sobre essa questão. Algumas dissertações e teses já começaram a abordar essa temática. Diante de órgãos governamentais como o Ministério da Saúde que, em 2007, relembrava em cartazes distribuídos em serviços de saúde que "muitas vezes praticamos o racismo e nem percebemos" constitui prova contundente de que esse problema continua a existir. À medida que tais estudos e pesquisas avançam, certamente deve recrudescer essa questão do racismo, não apenas na sociedade brasileira como entre os pro- 
fissionais de enfermagem, nosso foco especial de atenção.

É preciso lutar pela igualdade de oportunidades no acesso aos estudos e ao trabalho, assim como pela manutenção do emprego, independentemente de raça ou cor, por meio de campanhas de conscientização e orientação a gestores a fim de prevenir práticas discriminatórias. (Noelma Sandra)

Gonçalves estudou a temática sobre " $a$ invisibilidade da mulher negra na enfermagem profissional brasileira" e concluiu que são raras as enfermeiras negras em posições e cargos de comando como diretoras de departamentos de enfermagem em grandes hospitais e outros órgãos públicos de saúde ou ainda na direção de instituições de ensino e pesquisa. À maioria delas ainda cabe um trabalho subalterno na assistência direta ou na coordenação de unidades de internação de pequeno e médio porte em hospitais de segunda linha.

Ao levantar esta questão do racismo dentro da profissão, espera-se que tenha sido concretizado o objetivo inicial de contribuir em pesquisas sobre a participação do negro na Enfermagem Brasileira e, mesmo no mundo. Foi citado o exemplo da Dra Mary Elizabeth Carnegie, enfermeira negra, norte-americana, que também sofreu forte discriminação racial, em seu próprio país, não apenas por parte da sociedade em geral, mas dentro da própria profissão. Após varias lutas travadas por ela na sociedade em que vivia, deixou um grande exemplo positivo para todos os enfermeiros negros do mundo, que independentemente da cor da sua pele e de sua origem, todos tem valor.

\section{REFERÊNCIAS}

- Borenstein, M. S. O (1998) uso da história oral como uma possibilidade reconstruir a história da enfermagem. Texto Contexto Enferm. 7(1): 58-70.
- Collière, M. F. (1989) Promover a vida. Lisboa: Sindicato dos Enfermeiros Portugueses.

- Garcia, T.R. (1993) Eugenia! In hoc signo vinces: um aspecto do discurso sanitário da enfermagem, 1932 a 1938 / Eugenia! In hoc signo vinces. Rev. Bras. Enfermagem; 46 (3/4): 189-98.

- Jezuino, A. L. (1997) Perfil Social da População Negra no Brasil, Rev. Bras. Enf. Brasília, v. 50, nº 4, p. 485-496, out/dez.

- Molina T.M. (1973) Historia de La Enfermería. 2a edição. Inter-Médica, Buenos Aires.

- Munanga, K. (1990) Racismo da desigualdade à intolerância. São Paulo em Perspectiva, 4(2): 51-54.

- Oguisso, T., Souza Campos, P.F., Moreira, A. (2011) Enfermagem Pré-Profissional no Brasil: questões e personagens. Disponível em: <http://revista.portalcofen. gov.br/index.php/enfermagem/issue/view/5/showtoc >. Acesso em: 2/2/12.

- Sandra, N. Abaixo-assinado pela ratificação da convenção 189 e da recomendação 201 da OIT. Disponível em: <http://www.cut-se.org.br/ponto-de-vista/artigos/260/ superar-o-racismo-no-mundo-do-trabalho-um-desafio-posto-ao-movimento-sindical acesso 14/4/13

- Santiago, E. S.; Oguisso, T.; Campos, P. F. S.(2010) Racismo e Preconceitos: depoimentos de enfermeiros afrodescendentes egressos da Escola de Enfermagem da Universidade de São Paulo. Rev. Pesquisa: cuidado é fundamental, online. out/dez. 2 (4): 1303 - 1312.

- Santos, R. A. (2005) Quem é bom, já nasce feito? Uma Leitura do Eugenismo de Renato Kehl (1917-37). Rev. Intellectus/Ano 04 Vol. II. www2.uerj.br/ intellectus, acesso: 24/01/13.

- Siles González, J. (2011) Historia de La Enfermeria. Difusión Avances de Enfermería, Alicante

- Silva, M. P. (2002) Identidade e consciência racial brasileira. In: Seyferth. Racismo no Brasil, Fundação Petrópolis, Abong, São Paulo.

- Tompkins-McCaw Biblioteca de. Ciências da Saúde da Virginia Commonwealth University. Coleções Especiais e Arquivos.http://www.library.vcu.edu/tml/speccoll/vnfame/carnegie.html, acesso: 24/01/13. 